\title{
La heterogeneidad discursiva en los libros de viajes de Domingo Faustino Sarmiento y Justo Sierra O'Reilly
}

\section{Discursive Heterogeneity in the Travel Books of Domingo Faustino Sarmiento and Justo Sierra O'Reilly}

\section{Romina Abigail España Paredes*}

ResUMEN: En este artículo se analiza la heterogeneidad discursiva que caracteriza los libros de viajes de dos letrados latinoamericanos del siglo XIX, el argentino Domingo Faustino Sarmiento y el mexicano Justo Sierra 0 'Reilly. Se parte del complejo contexto de la producción de sus obras desde los márgenes políiticos y se analizan, en cada caso, los diferentes discursos secundarios que atraviesan sus obras, entre ellos el ensayístico, el epistolar, el narrativo y el histórico. A partir de este estudio se concluye que la heterogeneidad discursiva presente en dichas obras es una apropiación creativa del género de viajes como respuesta a los contextos e ideales políiticos de ambos viajeros.

PALABRAS CLAVE: Heterogeneidad; Literatura de viajes; Latinoamérica; Nación.

ABSTRACT: This article analyses the discursive heterogeneity that characterizes the travel books of two Latin American writers of the nineteenth century, the Argentinian Domingo Faustino Sarmiento and the Mexican Justo Sierra O'Reilly. The author looks into the complex context of the production of their books and analyze in each case the different discourses: essay, narrative and historical. From this study it is concluded that the discursive heterogeneity is an appropriation of the travel genre in response to their contexts and political ideals.

KEY woRDS: Heterogeneity; Travel Writing; Latin America; Nation.

Recibido: 22 de marzo de 2018

Aceptado: 27 de junio de 2018

* unam-Centro Peninsular en Humanidades y Ciencias Sociales/Consejo Nacional de Ciencia y Tecnología (romina.espana@gmail.com). 


\section{INTRODUCCIÓN}

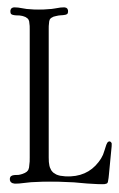

a dificultad por una definición genérica de la literatura de viajes ha sido señalada constantemente por la crítica. Su carácter liminal frente a otros grandes géneros discursivos ha hecho de su estudio una labor compleja, en la que se suele considerar la diversidad de sus registros discursivos como una de sus propias cualidades. Al retomar el planteamiento de Mijaíl Bajtín sobre los géneros discursivos, Beatriz Colombi define esta heterogeneidad en la literatura de viajes en términos de un género "secundario" o "ideológico". En sus palabras:

Podemos pensar el viaje como un género discursivo secundario o ideológico que aloja en su interior a géneros discursivos menores o primarios, como guías, mapas, cartas, tablas, itinerarios, cronologías, instructivos, descripciones, dibujos. Estas formas primarias no son narrativas sino enumerativas, descriptivas o estadísticas, incorporándose como "pruebas" o "constancias" del fundamento empírico de aquello que se cuenta, y tienen la función de reafirmar la propiedad documental del género, cuya importancia más evidente es la presencia de numerosos referentes externos, como por ejemplo, los topónimos (Colombi 2010: 291 y ss.).

Para Colombi, en la literatura de viajes interactúan enunciados primarios, definidos por Bajtín como formas simples de comunicación, en su mayoría determinadas por la inmediatez de su interlocución, como es el caso de réplicas del diálogo cotidiano o las cartas (Bajtín 2003: 250). No obstante, a mi parecer, la heterogeneidad de discursos en la literatura de viajes, caracterizada por la independencia de sus formas y estructuras, abarca una dimensión de mayor complejidad en este género, especialmente en el caso de los relatos de viajes escritos por las élites latinoamericanas en el siglo XIX que son, sin lugar a dudas, apropiaciones particulares de este género secundario.

Lo anterior es evidente si tomamos en cuenta la teoría de la enunciación y la visión de Bajtín en torno a la formación histórica de los géneros, así como la relación entre el lenguaje y la ideología. Para Bajtín, los enunciados primarios son absorbidos por discursos secundarios, con lo que 
pierden su relación inmediata con la realidad y con los enunciados reales. En este sentido, los enunciados secundarios se desarrollan en condiciones de comunicación culturalmente más complejas y organizadas, como son el ámbito artístico, científico y sociopolítico. Con ello, señala que los estilos genéricos se encuentran determinados por las esferas de la actividad y condición humana.

La complejidad comunicativa de la literatura de viajes en el contexto latinoamericano del siglo XIX, especialmente en un momento de definición de identidades nacionales, explica en gran medida que en sus obras no sólo observemos la asimilación de discursos menores o primarios por uno secundario, tal como lo plantea Colombi, sino también la confluencia de diversos discursos secundarios (a su vez compuestos por enunciados menores), como son los géneros ensayístico, literario o historiográfico. Al ser enunciados secundarios, cada uno de estos discursos contempla una "esfera de comunicación" independiente, caracterizada por su contenido temático, estilo y composición. Considero que la independencia y la articulación de estas totalidades enunciativas, en obras configuradas por la narración del viaje, definen la complejidad de la heterogeneidad discursiva en las literaturas de viajes latinoamericanas del siglo XIX.

En el presente trabajo me referiré a esta compleja diversidad de enunciados como "heterogeneidad discursiva" del relato de viaje. Las dos obras en las que desarrollaré el análisis de dicha heterogeneidad serán: Viajes por Europa, África y América, 1845-1847, del argentino Domingo Faustino Sarmiento (1811-1888), e Impresiones de un viaje a los Estados Unidos y al Canadá, del mexicano Justo Sierra O'Reilly (1814-1861). ${ }^{1}$ Ambos libros de viajes forman parte del contexto latinoamericano de conformación de identidades nacionales. Dividiré este artículo en cuatro apartados: primero, presentaré algunos aspectos del contexto latinoamericano de mediados del siglo XIX, y plantearé en qué sentido la heterogeneidad discursiva de sus obras responde a una "apropiación" del género de viajes; segundo y tercero, analizaré en cada caso el contexto de sus viajes y la heterogeneidad discursiva de sus obras, y cuarto, concluiré con una

1 En adelante, me referiré a estas obras como Viajes e Impresiones, respectivamente. 
reflexión sobre aspectos compartidos de dicha heterogeneidad y la configuración ambivalente de la nación.

\author{
NACIÓN, ÉLITES LETRADAS Y APROPIACIONES \\ DEL GÉNERO DE VIAJES EN AMÉRICA LATINA
}

Las independencias latinoamericanas ocurridas a principios del siglo XIX fueron un fenómeno que, al igual que la Conquista y la Colonia, conectaron el devenir político de los países de esta región. Para las jóvenes naciones latinoamericanas independizarse de la metrópoli española significó enfrentar similares condiciones económicas y sociales heredadas del sistema colonial, ${ }^{2}$ así como definir un nuevo orden político por parte de las élites criollas, ahora situadas en los espacios de poder.

Las élites criollas del siglo XIX estaban conformadas por una minoría privilegiada de herederos de la cultura europea que, una vez alcanzadas las independencias frente a la metrópoli, obtuvieron el dominio político de sus países. De este modo, siguiendo la reflexión de Ángel Rama (1984) y su análisis de la "ciudad letrada" colonial, es posible asociar a las élites criollas con el sector de los letrados que en las ciudades latinoamericanas asumieron el papel de organizar, diseñar e imaginar el orden de sus sociedades a través de la escritura. Al respecto, en su estudio de la historia intelectual de Argentina y México, Friedhelm Schmidt-Welle (2014) distingue entre letrados de la primera mitad del siglo XIX y los intelectuales del XX. ${ }^{3}$

2 En el caso de Argentina y México, las primeras décadas del siglo XIX conformaron una etapa en la que se perfilaron tres problemáticas relacionadas entre sí. La primera de ellas fue el derrumbe de la unidad colonial que había mantenido a estos dos países configurados en virreinatos; la segunda consistió en los diversos esfuerzos y fracasos constitucionales por consolidar repúblicas representativas; y la tercera fue el enfrentamiento entre grupos políticos pertenecientes a las élites criollas.

3 "Los primeros [letrados] realizaron el proyecto de la independencia de Hispanoamérica, es decir, muchas veces participaron en los sucesos históricos y en las luchas políticas por la independencia de manera inmediata y, casi sin excepción, ocuparon puestos o funciones importantes en instituciones del recién fundado Estado nacional" (Schmidt-Welle 2014: 16). 
El caso de los primeros ilustra bien el papel político e ideológico que jugaron Domingo Faustino Sarmiento (en Argentina) y Justo Sierra O'Reilly (en México), en el momento de escribir sus libros de viajes, ya que ambos participaron en los acontecimientos políticos de su contexto y ocuparon puestos políticos en sus convulsas naciones.

La élite criolla que había promovido la insurgencia tenía en sus manos el papel fundacional de la construcción de identidades nacionales. Mary Louise Pratt refiere a este proyecto ideológico criollo como una "lógica cultural euroamericana" (2010: 319), que conformó un sistema de ideas heredado de la época colonial y se tradujo en la apropiación de discursos en torno a la nación, el progreso, la modernidad. La literatura de viajes fue parte del repertorio de discursos que los letrados latinoamericanos se apropiaron para la construcción de sus naciones.

El auge que la literatura de viajes tuvo en el siglo XIX es, evidentemente, un referente imprescindible para analizar las obras Viajes e impresiones, debido a que fueron escritas siguiendo las nociones estéticas de lo que debía ser un relato de este género. La influencia de dicho género atravesó dos condiciones que caracterizaron el marco de elaboración de sus libros y que, en gran medida, son las responsables de las apropiaciones que Sarmiento y Sierra O'Reilly hicieron de ella: por un lado, el papel de la escritura en las ciudades letradas latinoamericanas del siglo XIX y, por el otro, la exaltación de Estados Unidos como el modelo de la nueva nación moderna.

Al hablar de "apropiación" me referiré a las adaptaciones "creativas" que en América Latina se generaron de modelos literarios de origen europeo, como es el caso del relato de viaje. En esta cuestión que ha sido abundantemente trabajada por la crítica, destaca el hecho de que, en las primeras décadas del siglo XIX, la literatura latinoamericana fue una suerte de realidad paradójica que, al mismo tiempo que seguía los modelos de una tradición cultural europea, presentaba una serie de transformaciones, apropiaciones o "transculturaciones", ${ }_{4}^{4}$ como resultado de su incorpora-

4 Esta categoría creada por el cubano Fernando Ortiz para criticar los conceptos de "aculturación" y "desculturación", los cuales formulaban una relación pasiva en el 
ción al circuito letrado y a los proyectos políticos de las élites criollas que lo conformaban.

En el caso de Sarmiento, los relatos de viajes eran parte del repertorio de lecturas que tenía al momento de escribir su propio libro, junto con numerosos textos sobre Europa. En el prólogo de Viajes hace una especial mención a este horizonte de lecturas, conformado por escritores románticos que definieron la fórmula literaria del relato de viajes decimonónico: "Sobre el mérito puramente artístico y literario de estas páginas, no se me aparta nunca de la mente que Chateaubriand, Lamartine, Dumas, Jaquemont, han escrito viajes, y han formado el gusto público" (Sarmiento 1996: XIV). De igual modo, Sierra O'Reilly estaba familiarizado con varios escritores de este género, a quienes también menciona a lo largo de Impresiones. Incluso, este autor era conocedor de la extensa tradición de libros de viaje elaborados por europeos y estadounidenses sobre Yucatán, y que en las primeras décadas del siglo XIX habían alcanzado éxito y proliferado en los periódicos locales El Registro Yucateco y El Museo Yucateco. Algunos de estos viajeros y sus obras fueron retomados en las discusiones del regionalismo yucateco con la finalidad de constituir los principios identitarios de la historia nacional de la región. Éste es el caso del viajero francés Frédéric Waldeck, el austriaco Emanuel von Friedrichsthal ${ }^{5}$ y el estadounidense John Lloyd Stephens. ${ }^{6}$ Cada uno de ellos formó

intercambio entre culturas, es retomada en los años ochenta por el uruguayo Ángel Rama en Transculturación narrativa en América Latina (2004).

5 Sierra O'Reilly mantuvo un diálogo con este viajero austriaco durante la primera mitad del siglo XIX acerca de la teoría del último sobre el origen de las pirámides (Taracena 2010: 169).

6 Este explorador estadounidense es conocido por su popular obra Incidents of Travel in Yucatan, que elaboró en 1843 como resultado de su visita a Yucatán por motivos diplomáticos. Sierra O'Reilly publicó su obra en cuatro entregas en El Museo Yucateco, y fragmentos de los capítulos 23 al 25 del segundo volumen del libro Incidents of Travel in Central America, Chiapas and Yucatan, mismo que en agosto de 1841 salió a la luz originalmente en inglés. Posteriormente, el escritor yucateco realizó la traducción del primer tomo de Viaje a Yucatán a finales de 1841 y principios de 1842, en 1848, y del segundo tomo en 1850. 
parte de las polémicas y los debates presentes en la obra periodística de Sierra O'Reilly en torno a cuestiones centrales de la identidad yucateca.

Conscientes de la tradición de la literatura de viajes, la apropiación que ambos letrados realizaron de este género es evidente en el carácter heterogéneo de sus discursos que, como he mencionado con anterioridad, se distinguió por estar compuesto no únicamente por diversos enunciados primarios, sino también secundarios. Como he destacado, dicho nivel de heterogeneidad discursiva responde a la complejidad comunicativa en la que estaban insertos los viajes de Sarmiento y Sierra O'Reilly, así como la escritura de sus obras. Podemos señalar que la esfera de comunicación de Viajes e Impresiones estaba determinada por tres condiciones similares: uno, las apropiaciones creativas que realizaron del género; dos, las condiciones de sus escrituras desde los márgenes políticos de sus países, y tres, la finalidad política de sus libros de ser proyecciones de un nuevo modelo de nación para sus países. Me detengo a analizar cada caso.

VIAJES DE SARMIENTO: ESCRITURA DESDE EL DOBLE

EXILIO Y DISCURSOS ENSAYÍSTICO, EPISTOLAR Y NARRATIVO

Los viajes de Sarmiento a Europa y Estados Unidos están enmarcados por los aludidos conflictos internos entre los federalistas rosistas y los unitarios exiliados, así como por los enfrentamientos externos entre Buenos Aires y otros países de América Latina durante la primera mitad del siglo XIX. Es sabido que desde temprana edad Sarmiento defendió la causa unitaria en contra de los federalistas, lo que provocó un primer exilio en Chile en 1831 debido al triunfo rosista y la derrota de los unitarios; desde 1839 cumplió en ese país una labor letrada como periodista y educador. ${ }^{7}$ En

Con el triunfo rosista y derrotados los unitarios, Sarmiento se desterraría a Chile en 1831 por primera vez, donde la República conservadora se había instaurado. Fue en 1836 cuando volvería a su provincia de San Juan. En 1839 apareció el primer número del periódico El Zonda, publicado por él, y que se convirtió en el "órgano oficioso" de la "Joven Argentina" (Ponce 1976: 45). 
enero de 1841, Sarmiento regresó a Santiago de Chile como un exiliado más del gobierno rosista. Durante este periodo se inauguró una etapa de maduración en sus id eas políticas, que enmarca su viaje a Europa y Estados Unidos entre 1845 y $1847 .{ }^{8}$

El 28 de octubre de 1845, Sarmiento partió rumbo a Europa desde Valparaíso en el buque de vela "Enriqueta", y durante su viaje de un año visitó Francia, España, Italia, Suiza, Alemania, Inglaterra, África y, finalmente, de manera improvisada, Estados Unidos. El 17 de agosto de 1847 partió rumbo a Nueva York en el vapor "Moctezuma", adonde llegó el 14 de septiembre. Durante los dos meses y medio que radicó en este país, también visitó Nueva Inglaterra, Búfalo, Albany, Troy, Niágara, así como las ciudades canadienses de Montreal y Quebec. Posteriormente, conoció Boston, Baltimore, Filadelfia, Washington, Harrisburgo, Cincinnati, Pittsburg y Nueva Orleans. El 14 de noviembre de 1847, se embarcó en el puerto de Nueva Orleans rumbo a Cuba. No dejó relatos de sus siguientes movimientos, pero se sabe que llegó a La Habana el 15 de noviembre de 1847, y desembarcó en Valparaíso el 24 de febrero de 1848.

Durante los dos años y tres meses de su viaje, Sarmiento mandó cartas dirigidas a sus amigos en Chile, quienes las publicaron en los periódicos locales. La crítica suele señalar que es probable que Sarmiento tuviera, desde el principio, la finalidad de editar sus impresiones en forma de libro; ${ }^{9}$ lo cierto es que dos años después de volver a Chile, en 1849, publicó la primera entrega de todas sus cartas con el título Viaje por Europa,

8 Gracias a su temprana amistad con la comunidad letrada de Santiago, pocos meses después de su llegada, Sarmiento ocupó el puesto de editor del periódico El Mercurio. También fue el editor de El Nacional. Con la victoria del presidente Bulnes, en 1842, Sarmiento fue designado director de la recién fundada Escuela Nacional de Santiago, y publicó en esa ciudad el periódico El Progreso. En 1843 entregó a los lectores $\mathrm{Mi}$ defensa, breve autobiografía que escribió en respuesta a los ataques de un representante del partido liberal chileno. El 2 de mayo de 1845 Sarmiento inició la publicación de su célebre obra Civilización y barbarie. Vida de Juan Facundo Quiroga en los folletines de El Progreso y de El Mercurio, y que apareció en forma de libro el 28 de julio del mismo año.

9 Véase Katra 1996: 854. 
África y América, que completó en $1851 .{ }^{10}$ Las once cartas que conforman esta obra están tituladas por los lugares visitados: 1) "Más a fuera", 2) "Montevideo", 3) "Río de Janeiro", 4) "Ruan", 5) "París", 6) "Madrid", 7 ) "África", 8) "Roma", 9) "Florencia", 10) "Suiza", y 11) "Estados Unidos".

Ahora bien, de especial interés para los objetivos de este análisis es la onceava carta, correspondiente al viaje de Sarmiento a Estados Unidos y que está dirigida a su amigo Valentín Alsina. ${ }^{11}$ Se trata de la última que conforma el libro y que, probablemente, Sarmiento despachó desde Panamá o cerca de su destino final en Santiago. Como señala William H. Katra (1996: 855), la decisión de viajar a Estados Unidos fue tomada por el escritor argentino a última hora, durante su visita a Inglaterra, donde leyó sobre los logros de la educación pública en el país americano alcanzados por Horace Mann, a quien conocería después en Boston.

Los probables motivos del viaje de Sarmiento a Europa suelen ser dos. Sus biógrafos tienden a destacar que fue una salida por parte del gobierno chileno ante los conflictos que el escritor argentino había generado entre las autoridades de este país, ${ }^{12}$ los cuales se habían agravado bajo la presión de Rosas. Sin embargo, también se reconoce la intención del viajero por conocer el funcionamiento de la educación pública en Europa y, finalmente, en Estados Unidos. Lo cierto es que el amigo de Sarmiento, Manuel Montt, entonces ministro de Justicia y de Educación Pública en el gobierno de Bulnes, le propuso realizar un viaje por cuenta del gobierno chileno a Europa y Estados Unidos con el objeto de estudiar el estado

10 Esta publicación realizada por la imprenta chilena Julio Belin no fue la única que se hizo en el siglo XIX, también fue reproducida por periódicos de Chile y Montevideo, y reimpresa en Buenos Aires en 1856.

${ }^{11}$ El argentino Valentín Alsina (1802-1869) era "hombre público, abogado, de destacada actuación contra el gobierno de Rosas. Exiliado en Montevideo, colaboró con el Comercio de Plata, de Florencio Varela y asumió su dirección a la muerte - por asesinato- de Varela. Escribió unas Notas al libro Civilización y barbarie" (Rojas 1996: 599). Asimismo, fue gobernador de la provincia de Buenos Aires en dos ocasiones: 1852 y $1858-1859$.

12 Este es el caso del enfrentamiento de Sarmiento con Domingo Santiago Godoy, liberal que estaba a cargo del periódico opositor El Siglo. 
de la educación elemental y los métodos de colonización en Argel. Este último es el motivo que Sarmiento expresa de manera explícita en su obra.

Al atender el complejo contexto político, considero que es posible reconocer una suerte de doble exilio en el viaje del escritor argentino a Europa. Es decir, al mismo tiempo que se encontraba en calidad de refugiado en Chile, su viaje a Europa fue una estrategia del gobierno chileno ante las crecientes presiones políticas que habían generado su participación en la vida pública. De este modo, es desde el doble destierro donde Sarmiento escribió las cartas que posteriormente conformaron Viajes. Lo cierto es que esta condición de destierro, que definió la escritura de sus viajes, se transformó en la segunda mitad del siglo XIX. ${ }^{13}$

Cabe señalar que Viajes es una obra donde se presenta una transformación del pensamiento político de Sarmiento. Como señala Gabriel Eduardo Brizuela, éste fue "un periodo de maduración de ideas, de confirmación y de decepciones. El sanjuanino estudió todos los sistemas políticos y se puede decir que eligió el que creyó, en ese momento, más apropiado" (2001: 109 y ss.). De este modo, Europa dejó de ser vista por él como el referente político ideal (postura defendida en Facundo, obra anterior a su viaje), y su lugar es ocupado por Estados Unidos. Este cambio en su pensamiento será un parteaguas para el proyecto de nación argentina que, más adelante, Sarmiento propondrá en sus obras posteriores.

Ahora bien, ¿cómo es la heterogeneidad discursiva en Viajes? Desde las primeras páginas del "Prólogo" el escritor argentino revela su visión sobre la complejidad de la escritura del viaje y la confluencia, en su interior, de formas diversas. En sus palabras:

13 Cuando Sarmiento regresó a Chile, el gobierno rosista se encontraba inmerso en una crisis agravada por los diferentes enfrentamientos civiles y la intervención francesa. Al mismo tiempo que publicó su libro Viajes en 1849, salió a la luz su obra Educación popular, y comenzó a editar el periódico La Crónica. La caída de Rosas en febrero de 1852 marcó un cambio en las condiciones políticas de Argentina y, de igual forma, significó la reintegración de Sarmiento a la vida política de su país en 1855. Así, pasaría de una condición de destierro político a ser gobernador de su provincia de San Juan de 1862 a 1864, y más tarde a ocupar la presidencia de la nación Argentina de 1868 a 1874. 
He escrito, pues, lo que he escrito, porque no sabría cómo clasificarlo de otro modo, obedeciendo a los institutos i a impulsos que vienen de adentro, i que a veces la razón misma no es arte a refrenar. Algunos fragmentos de estas cartas que la prensa de Montevideo, Francia, España o Chile han publicado, dan cumplida muestra de aquella falta de plan que no quiero prejuzgar; si bien me permitirá hacer indicaciones que no serán por demás, para escusar su irregularidad. Desde luego las cartas son de suyo jénero literario tan dúctil $i$ elástico que se presta a todas las formas $i$ admite todos los asuntos. No le está prohibido lo pasado, por la asociación natural de ideas, que a la vista de un hecho o de un objeto despiertan reminiscencias i sujieren aplicacion; sin que siente mal aventurarse mas allá de lo material i visible, pudiendo con propiedad seguir deducciones que vienen de suya a ofrecer al espíritu. Gústase entónces de pensar, a la par que se siente, $i$ de pasar de un objeto a otro, siguiendo el andar abandonado de la carta, que tan bien cuadra con la natural variedad del viaje (Sarmiento 1996: 9. Las cursivas son mías).

La configuración heterogénea que Sarmiento emplea en su obra, siguiendo el carácter dúctil y elástico del género, es evidente en la onceava carta, la cual es de relevancia para este análisis por tratar sobre su visita a Estados Unidos. Consciente de esta heterogeneidad de discurso, el autor divide la carta en una primera y segunda parte. En la primera, el escritor argentino comienza sus reflexiones sobre su viaje a los Estados Unidos adoptando la forma epistolar, la cual se distingue por marcas de interlocución que, desde un inicio, definen el lugar del lector explícito que acompaña al escritor a lo largo del texto:

\section{Sr. Don Valentin Alsina}

Noviembre 12 de 1847

Salgo de los Estados Unidos, mi estimado amigo, en aquel estado de excitacion que causa el espectáculo de un drama nuevo, lleno de peripecias, sin plan, sin unidad, erizado de crímenes que alumbra con su luz siniestra actos de heroísmo i abnegacion, en medio de los esplendores fabulosos de decoraciones que remedan bosques seculares, praderas floridas, montañas sañudas, habitaciones humanas en cuyo pacífico recinto reina la virtud i la inocencia (Sarmiento 1996: 290). 
En esta cita observamos que la forma epistolar que Sarmiento emplea en su obra es un modo de escritura referencial en donde, a la vez que se reconoce a un lector real (don Valentín Alsina) y el momento específico de la escritura, también es el punto de partida de un extenso discurso ensayístico en el que las marcas del "yo" de la enunciación asignan, de manera explícita, al viajero como escritor. Así, la voz enunciativa da forma al "yo" real desde la textualidad y, con ello, en relación con sus lectores.

A su vez, la carta es un tipo de género flexible que, como señala Mariana Ozuna, en el siglo XIX identificaba a los hombres letrados y se convirtió en una práctica social generalizada (escritura de cartas entre particulares, la lectura por divertimento de las correspondencias, la lectura de novelas epistolares) que llegó a tener mayor alcance que otros géneros, como el ensayístico. Sin embargo, la relación de este género con el ensayo es evidente en la narración, pues en ella "la carta puede convertirse en reflexión ensayística o narración literaria breve cercana al cuento, estos otros quehaceres son siempre mostrados como parte del mundo privado del remitente y el destinatario" (2010: 231).

En la primera parte de la onceava carta, la reflexión ensayística domina la temporalidad de la enunciación. De este modo, el carácter referencial del "yo" del discurso ensayístico (mismo que Sarmiento había inaugurado desde su obra Facundo), posiciona al escritor argentino en el centro temporal y espacial del relato, es decir, "cumple las mismas condiciones del aquí y el ahora: es el deíctico que permite organizar el discurso por referencia a quien toma la palabra" (Weinberg 2006: 79). Una condición de esta referencialidad tiene que ver con el hecho de que "yo", en este discurso, emplea siempre el tiempo presente para enunciar, estableciendo así el carácter "autodesignativo" de la voz enunciativa e indicando la posición de Sarmiento. De este modo, yo conforma un "aquí-ahora" absolutos, posición discursiva desde donde el viajero habla. En este caso, el tiempo presente del discurso genera el efecto de inmediatez de la escritura, el aquí-ahora es el momento en el que Sarmiento escribe Viajes. Siguiendo estas marcas del discurso, se podría decir que el lugar de enunciación del "yo" del viajero es el doble exilio, entre dos países que le eran extranjeros. 
Además de ser una forma discursiva referencial del sujeto real de enunciación, el ensayo es ante todo un discurso reflexivo donde el yo "se observa, examina e interpreta a sí mismo en el momento de la interpretación" (Weinberg 2001: 29). En relación con esta característica del género, Horacio Cerutti señala que el ensayo es "un texto reflexivo, en que la experiencia personal construye su materia misma, habla sobre los otros y los otros se expresan en él" (1993: 18). Este carácter reflexivo permite al viajero cuestionarse a sí mismo y analizar aquello que lo rodea, conformando una postura crítica que lo sitúa temporalmente en una distancia frente a "lo acontecido". Por lo tanto, no es casual que el género del ensayo esté ligado en su origen al del relato de viaje y compartan la distancia crítica y la fórmula reflexiva como parte central. ${ }^{14} \mathrm{El}$ discurso epistolar y el ensayístico posibilitan al viajero, junto con sus lectores, reflexionar de manera crítica sobre el desarrollo económico de Estados Unidos, su distribución demográica, su políitca de migración, así como otros aspectos que le son útiles para describir un modelo social y político del que el escritor argentino se asombra y que se distingue de lo que había observado en Europa, así como de lo conocido en América del Sur.

Asimismo, esta dimensión ensayística del discurso hace que el yo de Sarmiento dialogue no sólo con el destinatario y lector explícito de su carta (Alsina), sino también con una comunidad más amplia: sus compatriotas y amistades sudamericanas. Sus interlocutores, de este modo, son también aquellos con los que establece una relación de identificación, ${ }^{15}$ ya que reconoce su cercanía, sea por las experiencias históricas o las realidades sociales en común, o porque comparten el anhelo de descubrir un "nuevo mundo" en donde proyectar sus ideales políticos. De tal modo

14 Liliana Weinberg señala que el ensayo, junto con la literatura de viaje, surgen "en el momento en que el clima del Renacimiento y el Humanismo se apodera de algunas regiones de Europa y en el que comienza la etapa de grandes exploraciones, con la expansión sobre Affrica y Asia y muy especialmente con el descubrimiento de América" (2006: 247).

15 Tal como Sarmiento se identificaba con don Valentín Alsina, quien era un argentino que compartía la condición de exilio, en su caso en Montevideo, y también era un simpatizante de la causa contra Rosas. 
que este referente de identificación abarca a un grupo específico de criolos letrados con los que el escritor compartía sus intereses políticos y que, como él, se encontraban exiliados o enfrentados al gobierno de Rosas. Las representaciones del "nosotros" liberal, defensor de la República y prodestinatario de sus cartas, son evidentes en la onceava de ellas, dirigida a Alsina, ${ }^{16}$ en donde el escritor argentino define una postura ideológica sobre Estados Unidos:

Educado Ud. y yo, mi buen amigo, bajo la vara de hierro del más sublime de los tiranos, combatiéndolo sin cesar en nombre del derecho, de la justicia, en nombre de la república, en fin, como realización de las conclusiones a que la conciencia y la inteligencia bumana han llegado, Ud. y yo, como tantos otros nos hemos envanecido y alentado al divisar en medio de la noche de plomo que pesa sobre la América del sur, la aureola de luz con que se alumbra el norte. Por fin, nos hemos dicho para endurecernos contra los males presentes: la república existe, fuerte, invencible; la luz se hace; un día llegará para la justicia, el derecho; la luz se indicará hasta nosotros cuando el Sur refleje al Norte. iY cierto, la república es! [...] Así, pues, nuestra república, libertad i fuerza, inteligencia $i$ belleza; aquella república de nuestros sueños para cuando el mal aconsejado tirano cayera, i sobre cuya organizacion discutíamos candorosamente en el destierro, i bajo el duro aguijon de las necesidades del momento; aquella república, mi querido amigo, es un desiderátum todavía, posible en la tierra si hai un Dios que para bien dirije los lentos destinos humanos [...] (Sarmiento 1996: 290 y ss. Las cursivas son mías).

El "nosotros" es el que comparte una visión sobre los problemas que enfrenta la "América del Sur", así como las ideas de "nuestra república", aquella imaginada por otros argentinos en el destierro y que era anhelo político según los principios ilustrados de la "igualdad", la "justicia" y la "razón". ${ }^{17}$

16 Desde Facundo, Sarmiento identifica en Alsina un interlocutor de sus ideas políticas, donde reconoce el papel que el catedrático tuvo en la Universidad en la formación de esta nueva generación de jóvenes (véase Sarmiento 1977: 226 y ss.). Al mismo tiempo, es conocida la carta de Sarmiento dirigida a Alsina, en relación con las notas críticas que este último realizó al Facundo.

17 Ideas que Noé Jitrik define como una "ideología iluminista" que condiciona los planteamientos de Sarmiento en Facundo (1977: XXI). 
Para Sarmiento se trata de la "nueva" generación de jóvenes que, lejos del federalismo rosista y los viejos temores de los "antiguos unitarios", promovieron la "civilización europea" desde las letras. ${ }^{18}$ Para Sarmiento, éstos son los miembros del grupo criollo autorizado para formular una idea de nación desde su mirada privilegiada y alejada de la barbarie, así como para emitir un juicio justo sobre América del Sur y su porvenir.

Por su parte, en la segunda mitad de la carta, la fórmula del viajero-ensayista que Sarmiento había adoptado en la primera parte para legitimar sus interpretaciones comparativas y críticas sobre Argentina, se transforma completamente. De este modo, además de la identidad de un "yo" referencial (presente absoluto de aquí-ahora) y un "tú" (explícito e implícito) que, a su vez, representa a un "nosotros" latinoamericano, también surge una "identidad narrativa". Se trata de una identidad ligada al personaje, es decir, el sujeto que realiza en un tiempo y espacio determinadas acciones: en este caso, el viajero-personaje que narra en primera persona del singular su inscripción dentro de su viaje por los Estados Unidos.

Este segundo apartado comienza con el encabezado "Incidentes de viaje" y se divide en otros títulos en los que el viajero indica la ciudad sobre la que escribe. Para justificar esta separación entre la primera y la segunda parte de la carta, Sarmiento señala: "Mis aventuras de viaje en los Estados Unidos no merecen intercalarse entre las reflexiones que el espectáculo de aquel país me ha sugerido, por lo que no referiré a Ud. sino algunas que creo pueden interesarle" (1996: 369). De este modo, rompe con una de las estrategias más comunes del relato de viaje que es intercalar la narración de los acontecimientos vividos con los comentarios reflexivos o personales.

Esta separación por apartados entre ensayo y narración destaca la particular apropiación que Sarmiento realizó del género de viajes. Esta adaptación responde a que el autor buscaba generar dos efectos diferen-

18 José Campobassi destaca que Sarmiento, en este momento, se separa del unitarismo rivadavino y del federalismo rosista ya que, en su opinión, se trataban de dos sistemas inoperantes. La esterilidad de estos enfrentamientos en Argentina, es lo que lleva al escritor a defender en el Facundo "un federalismo tibio, mechado con algunas ideas unitarias" (Campobassi 1975: 244), lo que en esta obra llama "unitaria, federal, mixta". 
tes en sus lectores: mientras que el ensayo perseguía justificar y autorizar las reflexiones críticas del viajero frente a sus compatriotas, la narración pretendía recrear el aspecto literario de las "impresiones de viaje". Sobre esta cualidad literaria, tenía como referentes a escritores europeos que colocaban al viajero como protagonista, quienes, según sus palabras, "hermoseando sus cuadros casi siempre con las ficciones de la fantasía, o bien apropiándose de acontecimientos dramáticos ocurridos atrás" (Sarmiento 1996: 8), no dejaban saber qué era verdad y qué era fantasía. Sarmiento intentó distanciarse de este tipo de "impresiones" y señaló que en su época no eran comunes este tipo de excitaciones de viaje, sino que predominaba la monotonía de lo cotidiano que se sumaba a la falta de cosas nuevas por describir. Probablemente, esta idea que Sarmiento planteó en su "Prólogo" puede justificar la separación, en la onceava carta, entre un primer discurso ensayístico del viaje, y otro narrativo.

En esta segunda parte de la carta siguen existiendo las marcas epistolares que señalan la interlocución con un lector explícito, pero a diferencia del "yo" referencial del discurso ensayístico, situado en el tiempo presente de la escritura y que define un "aquí y ahora absolutos" de la enunciación, el "yo" del viajero se ubica en un espacio y tiempo pasado, localizado en el momento del viaje que, como sabemos, no corresponde al tiempo presente de la escritura y de la enunciación. Como claro ejemplo de la compleja heterogeneidad de Viajes, observamos que el discurso secundario epistolar presenta una articulación diferenciada, entre la primera y la segunda parte de la onceava carta, con los a su vez discursos secundarios del ensayo y la narración.

Por su parte, la trama de la carta configura una cronología que organiza la concordancia de la narración del viaje, es decir, el tiempo y el espacio de los acontecimientos. Así, el tiempo de la narración está unido a las acciones que el viajero refigura en su relato y que tienen su punto de partida en los últimos días de julio de 1847, cuando Sarmiento se encontraba todavía en París. En este momento, el viajero se refiere a sí mismo en tiempo pasado: "Tomando balance a mi bolsa en París, hallé los primeros días de julio que me quedaban escasos, cosa de 600 duros" (Sarmiento 
1996: 368). Esta narración secuenciada es la responsable de generar una síntesis de lo beterogéneo de los eventos del viaje, en la medida que ordena en este marco temporal la mención de los hechos vividos por el viajero-personaje, héroe y protagonista del relato. De este modo, se crea una identidad narrativa del viajero como un personaje central de la trama, una vez más, como parte de un discurso autobiográfico. ${ }^{19}$

\section{IMPRESIONES DE SIERRA O'REILLY: ESCRITURA DESDE}

\section{LOS MÁRGENES Y DISCURSOS ENSAYÍSTICO, NARRATIVO E HISTÓRICO}

Por su parte, el viaje de Justo Sierra O'Reilly a Estados Unidos en 1847 está enmarcado en los enfrentamientos del Yucatán federalista y el gobierno centralista. Desde la rebelión de Santiago Imán en 1838, se produjo una primera ruptura de Yucatán con México, que marcó el inicio de una etapa independentista a lo largo de 1840 y $1847 .{ }^{20}$ Durante este periodo, Sierra O’Reilly jugó un papel central como figura política y representante de la

19 La autobiografía, en palabras de Philippe Lejeune, se define como "relato en prosa que una persona real hace de su propia experiencia, poniendo énfasis en su vida individual y, en particular, en la historia de su personalidad" (1994: 50). No obstante, resulta necesario señalar que estas "narrativas" autobiográficas, denominadas por Leonor Arfuch (2013) como "narrativas del pasado reciente", además de presentar un tema simbólico de protagonismo autoreferencial, pueden configurar formas híbridas o intersticiales que rompen con aquellas canónicas de testimonio (memorias, biografías, autobiografías, entrevistas, relatos de vida). Estas formas híbridas infringen los límites genéricos y con ello, los "umbrales de la intimidad". Para un acercamiento al género autobiográfico en las letras mexicanas y argentinas del siglo XIX, véase Viveros 2015.

20 Durante este periodo se perfilaron dos facciones políticas dentro la élite yucateca, "una que trabajaba a favor de consolidar el gobierno independiente y la otra, que pugnaba por mantener la separación mientras se lograba el triunfo del federalismo en México" (Taracena 2010: 74). En un primer momento, la minoría centralista en Yucatán apoyaba una separación táctica, mientras que la mayoría se inclinaba por la independencia, entre ellos el líder de los campechanos y futuro suegro de Sierra O’Reilly, Santiago Méndez Ibarra, y el de los meridanos, Miguel Barbachano Tarrazo. 
facción federalista. ${ }^{21}$ Su importante labor se manifiesta en los cargos públicos que asumió durante el gobierno de su suegro, Santiago Menéndez Ibarra, así como por su papel de escritor y periodista. ${ }^{22}$

Cuando Sierra O'Reilly fue comisionado por el gobernador de Yucatán para viajar a Washington en septiembre de 1847, la llamada "Guerra de castas" ${ }^{23}$ ya había manifestado sus primeras amenazas a la élite regional

21 En este momento, Sierra O'Reilly es nombrado secretario del coronel don Sebastián López de Llego, quien combatió en Campeche a los partidarios del centralismo. Carlos Sierra (1996) explica que al triunfar la causa federal se designó al escritor como juez de distrito de Campeche. En este año la revolución federalista derrotó a los centralistas y restableció la Constitución General de 1824, y la local de 1825. En este contexto de separación de Yucatán de la República Central, en 1841, el vicegobernador de Yucatán, Santiago Méndez Ibarra (futuro suegro de Sierra O'Reilly), lo comisionó para concertar con los estados del sur una posible alianza para enfrentarse a los atropellos cometidos por el gobierno del centro. Al volver a Yucatán, interviene en el convenio que el gobierno de la península celebró con el de la República el 29 de diciembre de 1841.

22 Desde enero de 1841, publicó en Campeche El Museo Yucateco (1841-1842), primer periódico literario en Yucatán, el cual se insertaba en un momento particular de la literatura mexicana que "planteaba regenerar la opinión pública por medio de la educación, la literatura y el arte" (Taracena 2007: 14). En estos escritos, Sierra O’Reilly promovió la idea de Yucatán como una nación, fundada en un pasado propio y en una serie de valores compartidos, que reafirmaban la supremacía de los criollos en la región. Asimismo, en El Museo Yucateco, Sierra O'Reilly publicó por entregas varias obras literarias de corte primordialmente histórico y bajo el influjo del romanticismo europeo, tales como El Filibustero, Doña Felipa de Sanabria y Los bandidos de Valladolid. En de 1845, Sierra O'Reilly fundó su segundo periódico, El Registro Yucateco que, con bastante irregularidad, prolongó su existencia hasta 1849. En él dio a conocer otras de sus novelas por entregas, entre ellas: El secreto del ajusticiado y Un año en el hospital de San Lázaro. Sobre Sierra O'Reilly como precursor de la novela histórica y del folletín en México, véase Castro 2004.

23 Se llama "Guerra de castas" al cruento enfrentamiento entre población indígena del sur y oriente de Yucatán y los "blancos" o élite criolla de la región, que inició en julio de 1846 y se prolongó hasta 1901. Sobre la guerra de castas existe una vasta producción bibliográfica. El propio Sierra O'Reilly fue uno de los primeros en escribir sobre el conflicto. En su tercer periódico, El Fénix (1848), entre 1848 y 1851, publicó una serie de artículos acerca del tema, bajo el título de "Consideraciones sobre el origen, causas y tendencias de la sublevación de los indígenas, sus probables resultados y su posible remedio". Posteriormente, en 1857, estos artículos fueron publicados en Campeche de manera parcial en su obra intitulada Los indios de Yucatán. Consideraciones históricas sobre la influencia de elementos indígenas en la organización 
y, desde inicios de 1846, había iniciado la invasión de los Estados Unidos a México bajo el mando del presidente James Polk, quien defendía la doctrina expansionista bautizada como "Destino manifiesto" por John L. Sullivan, en 1845.

Sierra O'Reilly zarpó de la ciudad de Campeche en la goleta americana Essex, el 12 de septiembre de 1847 rumbo a Nueva Orleans, donde arribó el 4 de octubre. Poco después, se trasladó a Washington el 16 de noviembre del mismo año, y durante seis meses aproximadamente visitó otras ciudades de Estados Unidos, incluyendo un breve recorrido por la zona fronteriza entre dicho país y Canadá. Una vez fracasada la misión políica en los Estados Unidos que había motivado su viaje, emprendió el regreso a México el 16 de junio de 1848, donde desembarcó el 8 de agosto del mismo año. Durante su viaje, Sierra mantuvo un diario personal publicado póstumamente, ${ }^{24}$ del que se desprende la escritura de su libro Impresiones de un viaje a los Estados Unidos de América y al Canadá, publicado en cuatro libros en Campeche, en 1850 y $1851 .^{25}$

El viaje de Sierra O'Reilly a Estados Unidos consistió en una misión política que perseguía tres finalidades: uno, solicitar la desocupación de

social del país. Visiones críticas más recientes pueden encontrarse en Rugeley (2009) y Gabbert (2004).

${ }^{24}$ El Diario de mi viaje a los Estados Unidos está dividido en tres libretas. La primera abarcó el periodo comprendido entre el 12 de septiembre y el 31 de diciembre de 1847, y fue enviada a Yucatán en manos de su compañero de viaje Don Rafael Carvajal. La segunda contiene los apuntes del $1^{\circ}$ de enero al 29 de febrero de 1948, y la tercera comprende los escritos entre el $1^{\circ}$ de marzo y el 31 de mayo del mismo año. La publicación de este diario personal fue póstuma e intitulada Diario de nuestro viaje a los Estados Unidos (La pretendida anexión a Yucatán) por el historiador Héctor Pérez Martínez, quien en la primera mitad del siglo xx halló los manuscritos I y III en una librería de viejo de la Ciudad de México, los cuales publicó en el tomo 12 de la Librería Robledo, de José Porrúa e Hijos, en 1938. Fue años después que Manuel Porrúa encontró el tomo II del diario personal de Sierra O’Reilly, el cual Pérez Martínez había declarado perdido en 1938. El Segundo libro del diario de mi viaje a los Estados Unidos (La pretendida anexión de la Península de Yucatán a un gobierno extranjero) fue publicado en la Librería de Manuel Porrúa en 1953, y su trabajo paleográfico y de cotejo corrió a cargo de Marte R. Gómez.

25 Es importante mencionar que la obra Impresiones no se volvió a reimprimir sino hasta 2012, a partir de una edición realizada por Manuel Sol. 
Ciudad del Carmen, que había sido tomada por Estados Unidos; dos, conseguir para Yucatán un trato especial que garantizara la seguridad del estado ante cualquier medida represiva tomada por el gobierno mexicano contra él, tras su declarada neutralidad ante la guerra con Estados Unidos; y tres, pedir auxilio para el gobierno yucateco frente a los "indios rebeldes", quienes se habían levantado en armas en la "guerra de castas". No obstante, el crecimiento de las dificultades políticas y sociales durante el periodo de su viaje ocasionó que Sierra O'Reilly tomara nuevas medidas en su misión, e intentara negociar la soberanía de Yucatán a cambio de ayuda por parte del gobierno estadounidense. ${ }^{26}$

Durante los últimos meses de la misión de Sierra O'Reilly, en marzo de 1848, Santiago Méndez renunció a la gubernatura de Yucatán, y quedó en su lugar Miguel Barbachano. Cabe señalar que, a pesar de este cambio, los tratados de conciliación entre ambos bandos fracasaron y la guerra continuó a favor de los indios. ${ }^{27}$ El 16 de junio de 1848, la misión de Sierra O'Reilly se dio por terminada y, poco tiempo después, se declaró concluida la guerra con los Estados Unidos. Finalmente, Barbachano decretó la anexión de Yucatán a la nación mexicana de manera definitiva (Quezada 2001: 143).

De vuelta en Yucatán en 1848, el panorama político en relación con México se había transformado. De este modo, similar al caso de Sarmiento, quien escribió sus cartas de viajes desde un doble exilio, Sierra O'Reilly elaboró Impresiones en los márgenes políticos del México centralista, retomando las notas que había hecho durante su viaje en su Diario, el cual

26 Entre las dificultades durante su viaje se encontraban las constantes noticias de la cada vez más violenta guerra de castas, la incomunicación de la que era objeto, así como los enfrentamientos políticos entre la facción de Santiago Méndez y la encabezada por Miguel Barbachano. Por ejemplo, el 25 de marzo de 1848, durante los últimos meses de la misión de Sierra O'Reilly, "Santiago Méndez ya había renunciado a la gubernatura a favor de Miguel Barbachano, con quien se tenía la esperanza de entablar negociaciones, pues algunos rebeldes se identificaban con él, particularmente Jacinto Pat" (Quezada 2001: 142).

27 Fue el 14 de junio de 1848 cuando el gobierno de México otorgó la ayuda que Yucatán buscaba para reprimir la sublevación indígena, como parte de las gestiones de Barbachano. 
asumió la forma de un texto epistolar dirigido a su esposa Concepción Méndez. De la reescritura del Diario, así como de la incorporación de información e investigación historiográfica, resultan los cuatro tomos del libro Impresiones que verían la luz entre 1850 y 1851 en Campeche. Esta obra, lejos de ser un relato meramente anecdótico o una crónica de viaje, conjugó las ideas políticas regionalistas del escritor y promovió un proyecto político que criticaba el funcionamiento de la república mexicana y cuestionó el lugar de Yucatán en ella.

Es posible comparar el origen epistolar del diario de Sierra O'Reilly con la escritura de cartas que conforma Viajes de Sarmiento; no obstante, observaremos que el libro Impresiones elimina las marcas de interlocución del discurso epistolar. Asimismo, al igual que Viajes, de Sarmiento, Impresiones, de Sierra O'Reilly, presenta entre sus páginas una forma discursiva heterogénea en la que intervienen diferentes marcas subjetivas que colocan la voz del escritor en distintos tiempos y espacios. Si bien es posible reconocer puntos similares entre la heterogeneidad discursiva de la obra del autor mexicano y la del argentino, como en el caso de la presencia de los discursos secundarios del viajero-ensayista y del viajero personaje, también es interesante identificar cómo éstos son presentados de un modo disímil en Impresiones e, incluso, cómo en este libro aparece un tercer discurso, el del viajero historiador.

En esta obra, siguiendo la tradición del género, la narración del viaje ordena los demás discursos. Por lo tanto, desde el momento en que el escritor inició sus preparativos a finales de mayo de 1847 en Yucatán, la cronología de los acontecimientos vividos, así como los acontecimientos observados a lo largo de su viaje, conforman la diégesis central del texto. No obstante, las marcas de las fechas son parcialmente señaladas y la mayoría se desdibujan en los hechos descritos. En vez del viajero-personaje que en la carta de Sarmiento estaba separado del apartado del viajero-ensayista, en Impresiones se encuentra presente desde el principio y configura la trama de la cual Sierra O'Reilly es el protagonista, siguiendo la forma literaria de una autobiografía. Con ello, el viajero-personaje es aquel con quien comienza el relato, así como la voz narrativa desde su partida 
del puerto de Campeche hasta llegar a Estados Unidos. Se trata del propio escritor yucateco que asume la focalización central de la acción y la enunciación a lo largo de la obra, es decir, es el héroe y narrador de la historia.

Es posible reconocer la compleja imbricación de discursos secundarios en Impresiones al identificar cómo el discurso del viajero-ensayista aparece en el texto a modo de "pausa digresiva", es decir, como "aquellas interrupciones en el discurso narrativo para dar paso al discurso del narrador en su propia voz (generalmente un discurso tipo gnómico o doxal)" (Pimentel 2008: 51). Parte de la heterogeneidad discursiva de Impresiones es evidente en el cambio de temporalidad de la enunciación, dejando ver el paso de un discurso secundario a otro: la voz enunciativa del viajero-ensayista interrumpe la narración del viaje en tiempo pasado y emplea el presente de la escritura para desarrollar algún comentario que le permitirá hacer una crítica o justificación de su ideal político.

Ejemplo de lo anterior son las descripciones producidas por la narración del viaje, intercaladas con comparaciones que el autor realiza entre las costumbres políticas estadounidenses y las mexicanas, revelando las contradicciones y deficiencias de su propia sociedad. Este es el caso de la visita que realizó Sierra O'Reilly al presidente Polk en la Casa Blanca, en noviembre de 1847 , en la que el viajero se admiró de la austeridad con la que fue recibido. A partir de este momento, la voz del viajero-ensayista irrumpe en la narración con una crítica:

El que ha visto, como yo, no ya al presidente de la república mexicana cuya regia ostentación es al mismo tiempo una ridícula parodia de las cortes europeas y un cruel epigrama contra el espíritu de nuestras instituciones democráticas, sino a gobernadores de provincia y jefes militares rodeándose de un ejército de guardias, ayudantes, edecanes, caballerizos y dependientes de casa y boca, manifestándose al pueblo soberano con tanta pompa y majestad; y después haber visto al presidente de los Estados Unidos del Norte América en su modesta residencia, sólo acompañado apenas de un individuo de su familia, sin distintivo de ninguna clase [...]; la verdad, no podrá menos de hacer muy triste comparaciones en prejuicio de nuestras costumbres y hábitos republicanos (Sierra 2012: 286). 
A este modo de intercalar en la narración del viaje las diferentes digresiones críticas y reflexivas, se suma una de las condiciones que separa, a la vez que relaciona, las formas de escribir el viaje entre Sarmiento y Sierra O'Reilly. Mientras que el primero elabora sus discursos desde el doble exilio, el segundo escribe Impresiones en Campeche, poco tiempo después de su regreso de Estados Unidos. Sin embargo, es necesario destacar que, al igual que Viajes, la obra del yucateco fue hecha en un momento político en el que su posición, así como la legitimidad de su viaje, eran cuestionadas por sus contemporáneos. A diferencia del Diario epistolar dirigido a su esposa, del cual Sierra O'Reilly parte para elaborar su libro de viaje, Impresiones estaba dirigido al grupo político y letrado de Yucatán que, durante los últimos años de la primera mitad del XIX, había sufrido conflictos internos entre la facción representada por Barbachano y la encabezada por Méndez. Como se ha dicho, la victoria de los intereses de la primera derivó en la reincorporación de Yucatán a la nación mexicana en agosto de 1848, a escaso tiempo de finalizada la misión política en Estados Unidos. De este modo, al escribir su obra, había pasado de ser un representante del regionalismo yucateco y del grupo en el poder, a ser considerado un traidor a la patria y una figura del separatismo. Así, mientras Sarmiento le escribía a sus prodestinatarios, Sierra O’Reilly le escribía también a sus antagonistas.

Esta nueva condición política del escritor yucateco es una posible explicación del tipo de apropiación de la heterogeneidad discursiva del género de viaje que realiza en Impresiones. Por ejemplo, en el discurso ensayístico prevalecen enunciados apologéticos y didácticos en los que subyace, no sin algo de ambigüedad, una crítica profunda a las condiciones políticas de Yucatán y de México. Este discurso asume las marcas subjetivas del "yo" autoreferencial del viajero-ensayista, quien adopta la voz enunciativa y se posiciona en un aquí y ahora absolutos que corresponden al tiempo de la escritura. El "yo" reflexivo revela la polémica posición de los márgenes políticos desde donde el viajero elabora su obra.

Si bien podemos encontrar las marcas espaciales y temporales de Sierra O'Reilly como autor real ubicado en Campeche a lo largo del texto, 
ellas están dadas principalmente en la nota editorial que inaugura el primer libro de Impresiones. Este texto introductorio con el que el escritor inicia su edición de 1850 consiste en una especie de prólogo dirigido al señor don Alonso Aznar y Pérez, ${ }^{28}$ escrito en Campeche el $1^{\circ}$ de enero del mismo año, así como una introducción pública de su obra: "Mi buen y leal amigo: debo a usted la idea original de escribir y dar al público estas Impresiones de viaje; y por supuesto me atrevo a emprender una obra semejante, que en verdad no carece de dificultades, necesario es que usted se resigne a ver su nombre inscrito al frente de ella, aceptando la dedicatoria que le ofrezco" (Sierra 2012: 27).

A partir de esta nota, el discurso apologético del viajero está acompañado de un tono legitimador de su labor. Por un lado trata de justificar la importancia que tuvo su misión en el extranjero y por otro enaltecer su juicio acerca de Estados Unidos como, resultado de la experiencia producida por el contacto directo con esta sociedad. De esta experiencia parte el escritor para criticar y desacreditar las valoraciones hechas por sus compatriotas acerca de dicho país:

Mas volviendo al provecho que de esta obra puede sacarse, yo insisto en ello. Es notorio que he ido a ese país por asuntos del servicio público; servicio de que no tengo por qué sonrojarme ni arrepentirme jamás para que yo pensara en disimularlo. Esta circunstancia me ha ofrecido la ocasión de ser seguramente el único mexicano, que se hallaba en Washington al tiempo de las grandes discusiones del trigésimo congreso sobre la guerra de México, esa guerra injusta que ha dejado caer una fea mancha, no sobre el pueblo de los Estados Unidos en general; sino sobre la administración y el partido que la ha llevado a cabo. Además, yo estaba en contacto con muchos individuos notables de los que allí hacen la política, y creo que algunas especies han de ser enteramente nuevas para nuestros compa-

"Abogado, político, escritor, editor. Miembro de la Judicatura, recopilador de las leyes yucatecas de 1832 a 1850. Favorable a la unión con México y, a partir de 1846, opuesto al regionalismo de Sierra O'Reilly. Nació el 23 de junio de 1817, siendo hijo del capitán de milicias Benito Aznar Peón y de María Dolores Pérez del Mazo. Falleció el 20 de septiembre de 1861" (Taracena 2010: 388). Cabe señalar que Sierra O'Reilly critica a esta figura política en su Diario, donde lo acusa de ser responsable del cada vez más evidente fracaso de su misión como comisionado en Estados Unidos. 
triotas. Al menos, así me lo hace discurrir la equivocación con que he visto calificadas por escritores distinguidos algunas cosas y personas de los Estados Unidos (Sierra 2012: 28).

Este lector implícito, "nosotros" yucateco que abarca a sus "compatriotas", es a quien Sierra O'Reilly dirige la intención didáctica de Impresiones, ya que es al público que busca ilustrar y persuadir en materia política. Cabe señalar que los "compatriotas" comprenden un "nosotros" con los que por momento el escritor se identifica, y en otros (como en la cita anterior) se separa de ellos. Esta distancia estratégica que asume el viajero en determinados pasajes responde al objetivo didáctico del autor, mismo que era común en su obra periodística y literaria.

Aunque el texto introductorio dicta el modo en el que se presentará la voz autoreferencial, crítica y reflexiva del viajero-ensayista, como señalé anteriormente, esta forma digresiva aparecerá intercalada con la narración del viaje, recordando al lector el lugar desde donde escribe. Así, la identidad referencial del ensayista, por momentos, interrumpirá la síntesis de lo heterogéneo de la narración y suplirá la identidad narrativa. En este sentido, en Impresiones es posible reconocer distintas formas de identidad dadas por la heterogeneidad de sus discursos, los cuales mantienen las marcas subjetivas separadas unas de otras. Entre ellas se encuentra una tercera que comparte elementos de la identidad del viajero-personaje y del viajero-ensayista, pero que presenta un discurso independiente, regido por la voz del historiador.

Para hablar de este tercer enunciado, es necesario mencionar la importancia del discurso histórico en la abundante obra periodística y literaria de Sierra O'Reilly. ${ }^{29}$ La concepción de la historia que el autor tenía

29 Al respecto resulta interesante que a lo largo de Impresiones, Sierra O'Reilly menciona su reciente novela de tono histórico publicada poco antes de su viaje a Estados Unidos, Un año en el hospital de San Lázaro. Asimismo, en su Diario aparece un señalamiento sobre el comienzo de la escritura de su conocida novela histórica, La bija del judio, durante su viaje. Esta última, fue publicada por entregas en su periódico $E l$ Fénix a partir de 1848, poco tiempo después de su regreso de los Estados Unidos y dos años antes de la publicación de la primera y única edición de Impresiones. 
al momento de escribir Impresiones respondía al creciente interés que la memoria tenía en el contexto de la conformación de identidades nacionales en el siglo XIX, ya que la investigación del pasado y su reconstrucción adquirió vital importancia para la élite letrada en Yucatán, en tanto fue materia central para la configuración de una identidad regional..$^{30}$ En un ejercicio de memoria histórica, los eventos del pasado que Sierra O'Reilly intercala en la narración de su viaje en Impresiones no son exclusivos de Yucatán o México, sino que, en su mayoría, son acontecimientos históricos de la nación estadounidense que consideró relevantes para la comprensión y explicación de su funcionamiento como una nación moderna.

El discurso histórico en esta obra es un ejemplo de la apropiación que Sierra O'Reilly realizó de la heterogeneidad discursiva del género de viajes. El autor retoma este recurso para desarrollar extensas narraciones acerca de eventos acontecidos a distancia temporal del momento de la escritura de la obra y del viaje, lo que sin duda rompe con la narrativa de las "impresiones". Por lo general, se trata de datos sobre el pasado político que suceden a la información cartográfica y geográfica de cada una de las ciudades que Sierra O'Reilly visitó durante su viaje. Sin embargo, la reconstrucción de la historia estadounidense llega a extenderse desde su periodo colonial hasta los años de la misión política del yucateco en 1847 y 1848.

De este modo, en Impresiones podemos reconocer una heterogeneidad discursiva que está atravesada por una referencialidad multisituada, en la cual las críticas del "yo" autorreferencial del viajero-ensayista, ubicado en el presente de la escritura (Yucatán en 1850), interrumpen el discurso en tiempo pretérito del viajero-personaje (Estados Unidos entre 1847 y 1848) y, a su vez, son complementadas por el discurso del narrador-historiador, ubicado en un pasado más lejano. De este modo, el "yo" del discurso ensayístico será el referente del "aquí" y "ahora" que convierte en "allá" y "entonces" al tiempo y espacio del viaje y de la historia. Cada discurso secundario mantiene su propia temporalidad.

30 Sobre el caso de El Museo Yucateco, periódico editado por Justo Sierra O'Reilly, y el papel de la historia en la reinvención de la identidad yucateca, véase Taracena 2010. 
En esta triple temporalidad, el discurso histórico y el ensayístico son las formas enunciativas responsables de la ruptura cronológica de la narración de viaje. Al igual que la digresión del discurso ensayista en la narración, el enunciado histórico interrumpe con una "apertura performativa"31 o un tipo de "prefacio" en el que deja ver las marcas subjetivas de la voz de enunciación. Por ejemplo, Sierra O'Reilly dedica el capítulo II del segundo libro de Impresiones, en su totalidad, a elaborar una biografía de George Washington. En este caso, la "apertura performativa" del discurso histórico adopta también la perspectiva enunciativa del discurso ensayístico, situando la voz del viajero en el tiempo y espacio absoluto de la escritura:

Más yo creo, que lo poco que voy a decir, es indispensable para llenar cumplidamente el objeto de este pequeño libro. Tratándose de dar cuenta de las impresiones de un viaje, no se puede prescindir de hacer referencia de las que el escritor ha recibido. Ahora bien, la impresión mayor que se recibe en los Estados Unidos, es la que produce el nombre de GEORGE WASHINGTON (Sierra 2012: 247 y ss.).

Concluida la "apertura performativa" en forma de enunciación referencial y en tiempo presente, los pasajes históricos presentan una dinámica narrativa propia. En lo general, en estos pasajes desaparecen las marcas subjetivas de autoreferencialidad, por lo que son narrados desde la objetividad de un narrador externo a la diégesis. El enunciado del viajero-historiador adquiere un "efecto de realidad" (Barthes 2009) propio del discurso histórico. De hecho, podríamos decir que la heterogeneidad del discurso histórico, independiente a la temporalidad de la narrativa del viaje, aunque no siempre temáticamente del discurso ensayístico, permite

31 Roland Barthes desarrolla dos procedimientos del discurso histórico, el shifter de organización y los signos del enunciante (destinador); de este último forman parte las marcas subjetivas de la "apertura performativa". Barthes destaca que el shifter de organización, mediante el cual el historiador "organiza su propio discurso, lo retoma, lo modifica a lo largo de su camino; en una palabra, le asigna referencias explícitas" (Barthes 2009: 95), presenta la coexistencia de dos tiempos, el de la enunciación y el de la materia enunciada (el suceso histórico). 
a Sierra O'Reilly incluir la reflexión histórica como parte de su postura crítica frente a las condiciones políticas y sociales de México.

En Impresiones la narración de eventos históricos no tiene únicamente como objetivo construir un referente político, sino también es un esfuerzo del autor por hacer de su viaje un evento de la historia compartida entre Estados Unidos, México y Yucatán. Por tal motivo, algunos de los eventos del viaje son justificados también como sucesos de trascendencia histórica, de los cuales el propio escritor era testigo e, incluso, protagonista. Así, por un lado, la reconstrucción de la historia es el mecanismo propicio para presentar el desarrollo de la nación moderna como ejemplo; por otro, la historia de México y Yucatán es el marco de comparación a partir del cual Sierra puede señalar y criticar el origen histórico de los problemas contemporáneos que los aquejan. De ahí su importancia y su presentación como un discurso independiente y preponderante en Impresiones.

REFLEXIONES FINALES: HETEROGENEIDAD

Y CONTEXTOS AMBIVALENTES

Analizar la heterogeneidad discursiva de la literatura de viajes latinoamericana del siglo XIX es atender la apropiación o transculturación de este popular género entre las élites letradas, misma que estuvo mediada por la propia relación que los viajeros tenían con sus complejos y conflictivos contextos políticos. A lo largo de este trabajo he analizado cómo el género de viajes apropiado creativamente por dos representantes de la élite criolla de Argentina y México, Sarmiento y Sierra O'Reilly, se caracteriza por una heterogeneidad discursiva. En Viajes y en Impresiones esta heterogeneidad se presenta como una compleja relación de discursos secundarios, organizados por la narración del viaje, pero diferenciados por sus marcas temporales y de enunciación. El estudio de estos libros de viajes es ilustrativo sobre cómo los enfrentamientos entre facciones políticas, la labor de configuración de identidades nacionales, así como la necesidad de un 
referente político de nación en América Latina a mediados de siglo XIX, confluyen y definen las condiciones de comunicación de sus obras.

La riqueza discursiva de Viajes y de Impresiones es una muestra de que la escritura de viajes latinoamericana en dicho siglo conforma un género secundario que no sólo se constituye por discursos primarios (tal como señaló Colombi), sino que se configura a su vez de otros discursos secundarios. De ahí la complejidad y el valor de estos tipos de textos. En el caso de los libros de Sarmiento y Sierra O'Reilly observamos la confluencia de géneros autónomos (aunque con cierta imbricación y ambivalencia) como el epistolar, el ensayístico, el narrativo autobiográfico y el histórico. Si bien hemos reconocido el intento de la estructura narrativa del viaje por organizar y jerarquizar estos discursos secundarios, cada una de estas formas presenta marcas de enunciación y temporalidades que los diferencian entre sí, imposibilitando una homogenización de la voz del viajero y de sus enunciados. De hecho, se puede concluir que esta cualidad heterogénea del género es la que le permitió a los viajeros latinoamericanos apropiarse del género según sus necesidades y proyectar en sus obras los objetivos políticos que perseguían y la idea de nación que deseaban promover entre sus contemporáneos. Considero que la heterogeneidad discursiva del género de viajes, entendida como la convergencia de discursos secundarios, convirtió a este tipo de obras en documentos privilegiados para las élites letradas latinoamericanas. De este modo, ambos letrados recurrieron a la escritura de viajes con el fin de legitimar y autorizar sus ideas desde los márgenes políticos en los que se encontraban al momento de la producción de sus obras.

Sin duda, estudiar la literatura de viajes latinoamericana del siglo XIX, atendiendo su heterogeneidad discursiva, permite acercarse a las apropiaciones de géneros literarios realizadas por las élites criollas de la época, así como comprender las relaciones de los letrados con el contexto ambivalente de definiciones de identidades nacionales. 
BIBLIOGRAFÍA

ARFUCH, LEONOR. Memoria y autobiografía. Exploraciones en los límites.

México: FCE, 2013.

BajTín, Mijaíl. Estética de la creación verbal. Trad. Tatiana Bubnova. México: Siglo XXI Editores, 2003.

BarTheS, Roland. "El discurso de la historia". Françoise Perus (comp.). La bistoria en la ficción y la ficción en la bistoria. México: Universidad Nacional Autónoma de México, 2009. 93-106.

BRizuela, Gabriel Eduardo. Viajes por Europa, África y América: su significado en la evolución del pensamiento político de Domingo Faustino Sarmiento. San Juan: Facultad de Filosofía, Humanidades y Artes, 2001.

CAMPOBASSI, José S. Sarmiento y su época. Buenos Aires: Editores Losada, 1975.

CASTRO, German. "Justo Sierra O'Reilly: pionero de la novela histórica y de folletín en México", Caleidoscopio 16 (2004): 125-135.

CERUTTI, HoraCio. "Hipótesis para una teoría del ensayo". El ensayo en nuestra América: para una reconceptualización. México: Universidad Nacional Autónoma de México, 1993. 13-26.

Colombi, BeATRIz. "EL viaje, de la práctica al género". Mónica Marinone y Gabriela Tineo (coords.). Viaje y relato en Latinoamérica. Buenos Aires: Ediciones Katatay, 2010. 287-308.

GaBBERT, WOlfGang. "Of Friends and Foes: The Caste War and Ethnicity in Yucatán”. The Journal of Latin American Antbropology 91 (2004): 90-118.

JITRIK, NoÉ. "Prólogo". Domingo Faustino Sarmiento. Facundo. Caracas: Biblioteca Ayacucho, 1977.

Katra, William H. "Sarmiento en los Estados Unidos". Viajes por Europa, África i América, 1845-1847. Javier Fernández (coordinador). Madrid: ALLCA XX/Colección Archivos, 1996. 853-911.

Lejeune, PhiLIPPE. El pacto autobiográfico y otros estudios. Madrid: Megazul-Endymion, 1994. 
Ozuna, MARIANA. "Límites y alcances del género epistolar en México (1810 y 1811)". INTI, Revista de Literatura Hispánica 71/72 (2010): 229-241.

PIMENTEL, LUZ AURORA. El relato en perspectiva. México: Siglo XXI Editores, 2008.

Ponce, AníBAL. Sarmiento constructor de la nueva Argentina. Y la vejez de Sarmiento. Buenos Aires: Hachette, 1976.

PRATT, MARY LOUISE. Ojos imperiales. Literatura de viajes y transculturación. México: FCE, 2010.

QueZadA, Sergio. Breve historia de Yucatán. México: El Colegio de MéxiCO/FCE, 2001.

RAMA, ÁNGEL. La ciudad letrada. Hanover: Ediciones del Norte, 1984. . Transculturación narrativa en América Latina. México: Siglo XXI, 2004.

Rojas, Elena M. "Glosario. Índices onomásticos y toponímicos de Viajes". Viajes por Europa, África i América, 1845-1847. Javier Fernández coordinador. Madrid: ALLCA XX/Colección Archivos, 1996. 599-616.

RugelEy, TerRY. Rebellion Now and Forever: Mayas, Hispanics, and Caste War Violence in Yucatan, 1800-1880. Stanford: Stanford University Press, 2009.

Sarmiento, Domingo Faustino. Facundo. Caracas: Biblioteca Ayacucho, 1977.

Viajes por Europa, África i América, 1845-1847. Javier Fernández (coordinador). Madrid: ALLCA XX/Colección Archivos, 1996.

SCHMidT-Welle, FriedHelm. "Letrados e intelectuales en América y México". Firedhelm Schmidt-Welle coordinador. La historia intelectual como bistoria literaria. México, El Colegio de México, 2014: 15-34. 317-336.

SIERRA O'REILLY, Justo. Impresiones de un viaje a los Estados Unidos y al Canadá. Manuel Sol (editor). México: Universidad Nacional Autónoma de México, 2012.

TARacena Arriola, ArTURo. "El Museo Yucateco y la reinvención de Yucatán. La prensa y la construcción del regionalismo peninsular". Península II 1 (2007): 13-46. 
De la nostalgia por la memoria a la memoria nostálgica. México: Universidad Nacional Autónoma de México-Centro Peninsular en Humanidades y Ciencias Sociales, 2010.

VIVEROS, Luz AMÉRICA. El surgimiento del espacio autobiográfico en México. Impresiones y recuerdos (1893), de Federico Gamboa. México: Universidad Nacional Autónoma de México, 2015.

WeINBERG, LILIANA. El ensayo, entre el paraíso y el infierno. México: FCE/ Universidad Nacional Autónoma de México, 2001.

- Situación del ensayo. México: Universidad Nacional Autónoma de México, 2006. 